Copyright by the American Society of Agricultural and Biological Engineers. Kozarek, J. L.; Wolfe, M. L.; Love, N. G.; Knowlton, K. F., "Sorption of estrogen to three agricultural soils from Virginia, USA," Transactions of the ASABE. 51(5): 1591-1597. (doi: 10.13031/2013.25316) @2008

\title{
Sorption of Estrogen to Three Agricultural SOILS FROM VIRGINIA, USA
}

\author{
J. L. Kozarek, M. L. Wolfe, N. G. Love, K. F. Knowlton
}

\begin{abstract}
Land-applied manures and grazing livestock are sources of estrogens to the environment. Natural steroid estrogens such as $17 \beta$-estradiol (E2) in low concentrations $\left(\mathrm{ng} \mathrm{L}^{-1}\right)$ can adversely affect the reproductive health of aquatic organisms. The goal of this research was to quantify the sorption of E2 to three agricultural soils from different physiographic regions in Virginia, a critical step in predicting transport of estrogens in runoff from agricultural fields. Batch equilibrium experiments were conducted with a range of E2 concentrations (50 to $2000 \mu \mathrm{g} \mathrm{L}^{-1}$ ) in a background solution of $5 \mathrm{mM}$ calcium chloride and $100 \mathrm{mg} \mathrm{L}^{-1}$ sodium azide added to samples of Groseclose loam, Myatt sandy loam, and Cecil loam soils collected from the plow layer (0 to $15 \mathrm{~cm}$ ) in addition to a Cecil soil sample from the Bt horizon. The concentration of E2 in the liquid phase was measured by gas chromatography/mass spectrometry (GC-MS) and was used to develop sorption isotherms for each soil. The time required to reach apparent equilibrium for all soils was less than $24 \mathrm{~h}$. In general, the linear isotherm provided a good fit to model the sorption of E2 to agricultural soils from the plow layer $\left(R^{2}>0.9\right)$. The sorption of E2 to agricultural soil was correlated to the organic carbon content of each soil (Pearson coefficient, 0.79) with log $K_{o c}$ values ranging from 2.90 to 3.99 .
\end{abstract}

Keywords. 17 beta-estradiol, Estrone, Gas chromatography, Isotherms, Sorption.

A gricultural nonpoint-source (NPS) pollution investigations typically focus on a relatively narrow range of targeted toxic and nutrient compounds. However, regular application of pesticides, irrigation water, soil amendments, and fertilizers, including animal manure, may result in the transport of numerous other organic chemicals into surface waters via runoff and into groundwater via leaching. Of these organic chemicals, steroid hormones are of particular concern in the environment because they are bioactive at low concentrations. Natural steroid hormones such as estrone (E1) and 17 $\beta$-estradiol (E2) can have dangerous, endocrine-disrupting effects on humans and wildlife at concentrations as low as picograms or nanograms per liter of water (Colborn et al., 1993). Natural hormones are much more bioactive (have greater estrogenic activity) than synthetic estrogenic endocrine-disrupting chemicals such as pesticides and plasticizers (Matsui et al., 2000). Increased steroid estrogen concentrations in surface waters have resulted in a high incidence of intersexuality in wild populations of riverine fish and widespread sexual disruption in wild populations (Jobling et al., 1998).

Submitted for review in December 2007 as manuscript number SW 7306; approved for publication by the Soil \& Water Division of ASABE in August 2008.

The authors are Jessica Lindberg Kozarek, ASABE Member, Graduate Research Assistant, and Mary Leigh Wolfe, ASABE Fellow, Professor, Department of Biological Systems Engineering Virginia Tech, Blacksburg, Virginia; Nancy G. Love, Professor, Department of Civil and Environmental Engineering, University of Michigan, Ann Arbor, Michigan; and Katharine F. Knowlton, ASABE Member, Associate Professor, Department of Dairy Science, Virginia Tech, Blacksburg, Virginia. Corresponding author: Jessica L. Kozarek, 200 Seitz Hall (0303), Virginia Tech, Blacksburg, VA 24061; phone: 540-231-6509; fax: 540-231-3199; e-mail: jkozarek@vt.edu.
While a number of studies have quantified estrogens released from wastewater treatment plants (e.g., Ternes et al., 1999; Baronti et al., 2000; Kolpin et al., 2002; Andersen et al., 2003), it is more difficult to attribute estrogen pollution to nonpoint sources such as land-applied manure and animal grazing operations. The type and amount of estrogens in animal manures are dependent on the species and life stage (Shore et al., 1995; Lange et al., 2002). Estrogen in animal manures can be free or conjugated with sulfate or glucuronide groups (Hutchins et al., 2007). Conjugated forms of estrogens are more polar and may be transported more easily in runoff (Hanselman et al., 2003). To estimate the probability of estrogens in runoff and groundwater from land-applied manure, the concentrations of estrogens in livestock manure prior to land application need to be known, taking into account the degradation of estrogens in storage, handling, and treatment practices. Through a survey of dairy and swine manure storage facilities, Raman et al. (2004) determined that free estrogen concentrations are largely dependent on manure handling systems and reported E2 concentrations ranging from 0.8 to $49 \mathrm{ppm}$ in the storage facilities studied. To more accurately estimate the concentration of estrogen in landapplied manure, more extensive studies are needed that include a wide range of manure treatment and handling practices.

Estrogens can be transported to surface water via runoff after manure has been land-applied (Shore et al., 1995; Nichols et al., 1997; Finlay Moore et al., 2000). Predicting the environmental fate of estrogens from land-applied manure or grazing operations is complicated because of degradation of estrogens in the presence of microorganisms (Lee and Liu, 2002). Sorption to soil is an important component of the environmental fate of estrogens because it can slow the transport to surface water, allowing estrogen to be degraded to less bioactive compounds (fig. 1). Although studies such as those 

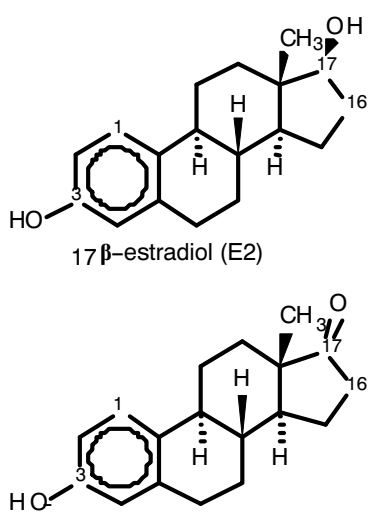

Estrone (E1)

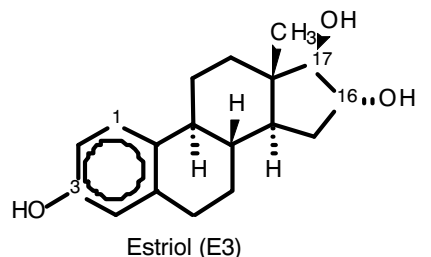

Figure 1. The molecular structures of 17ß-estradiol (E2) and degradation products estrone (E1) and estriol (E3) are characterized by similar ring structures with different functional groups at the $\mathrm{C}-17$ and $\mathrm{C}-16$ positions. As E2 degrades, the relative ratio of estrogenic activity decreases.

of Yu et al. (2004) and Lai et al. (2000) indicate that estrogens are strongly sorbed to soil, estrogens have been found in runoff from fields following application of chicken litter (Finlay Moore et al., 2000; Shore and Shemesh, 2003). The rate of estrogen degradation in soils is variable, ranging from 1 to 25 days; however, estrogen degrades faster in manureamended soils than in soils with no manure content (Lucas and Jones, 2006). More studies on sorption and degradation are needed to fully understand which factors are most important to predict concentrations in runoff from agricultural fields.

The specific objective of this study was to develop isotherm equations to describe the sorption of estrogen to agricultural soils in the absence of biodegradation. Because E2 is the most potent natural steroid estrogen (e.g., Matsui et al., 2000), it was chosen for the sorption experiments.

\section{BACKGROUND}

Lee et al. (2003) suggested that hydrophobic partitioning into organic carbon is the dominant mechanism for E2 sorption to soils. Hydrophobic, or linear, partitioning refers to the separation of nonpolar organic molecules out of the polar soil solution and into the nonpolar organic matter of the soil (Bohn et al., 2001). This mechanism is analogous to the partitioning of nonpolar compounds from a polar phase such as water into a nonpolar phase such as octanol. If hydrophobic partitioning is the dominant sorption mechanism, then the sorption of E2 to soils is expected to be highly correlated to organic matter or organic carbon content. Lai et al. (2000) reported correlation coefficients ranging from 0.86 to 0.94 for the sorption of free estrogens, including E2 and E1, to the total organic carbon (TOC) content of various sediments. Casey et al. (2003) found a correlation coefficient of 0.79 between the sorption of E2 and percent organic carbon. However, E2 sorption to iron oxide and clay minerals in the absence of organic carbon indicates that hydrophobic partitioning cannot be the only sorption mechanism (Lai et al., 2000; Van Emmerik et al., 2003). Lai et al. (2000) reported that $40 \%$ of the estrogen added to iron oxide (no organic carbon) was sorbed.

The three most common isotherms used to model sorption of contaminants to soils are Freundlich, linear, and Langmuir. Most E2 sorption studies reported in the literature have used the Freundlich isotherm to describe the sorption of E2 to soil (Lai et al., 2000; Casey et al., 2003; Lee et al., 2003; Yu et al., 2004). The published Freundlich parameters vary widely among different soils and sediments. It is unclear whether the wide variation in sorption isotherm parameters is due to soil properties or differences in experimental analysis. Although the sorption of E2 to soils and sediments is described as hydrophobic partitioning (e.g., Lee et al., 2003), only two studies, Lee et al. (2003) and Casey et al. (2005), developed linear isotherms to describe the sorption of E2 to soils and sediment.

There are discrepancies in the literature regarding the rate of estrogen sorption to soil. Lai et al. (2000) reported time to equilibrium on the order of $1 \mathrm{~h}$, while Casey et al. (2003) and Lee et al. (2003) reported time to equilibrium of 48 and $72 \mathrm{~h}$, respectively. Yu et al. (2004) reported apparent equilibrium within $48 \mathrm{~h}$ for aqueous estrogen concentrations of $25 \%$ to $50 \%$ of their solubility limits and 7 to 10 days for dilute estrogen concentrations (20 times lower than their solubility limits). These studies involved the sorption of estrogens to river sediments and soils with a wide range of properties. Because of this difference in sorption rates, all future studies should record data for a number of days to ensure that equilibrium has been reached. In addition, many studies did not attempt to sterilize the soil, and the calculated sorbed concentration could include loss of E2 due to degradation (Lai et al., 2000; Casey et al., 2003; Lee et al., 2003; Brion et al., 2004).

\section{Materials ANd Methods}

A series of batch equilibrium sorption experiments was conducted to determine partitioning of E2 between soil and aqueous phases. All sorption experiments were set up as continuously shaken, soil-water systems in $250 \mathrm{~mL}$ glass bottles with Teflon-lined caps. Each bottle contained a mass of soil as the sorbent and a concentration of E2 in a background solution as the sorbate. To eliminate as many sources of E2 degradation as possible, the soil-water systems in this experiment were chemically sterilized with sodium azide to minimize biodegradation and covered to minimize photolysis. Temperature was measured at every sampling time and was maintained at $22^{\circ} \mathrm{C} \pm 2{ }^{\circ} \mathrm{C}$. The $\mathrm{pH}$ was measured at various sampling times. The bottles were acid-washed, rinsed, and autoclaved prior to each use. Samples were taken from $24 \mathrm{~h}$ through 9 to 10 days to ensure that equilibrium was reached.

\section{Chemicals AND Solutions}

Stock solutions of E2 at concentrations of 100 and $500 \mathrm{mg}$ $\mathrm{L}^{-1}$ were made by dissolving E2 in high-performance liquid chromatography (HPLC)-grade methanol. All stock solutions were stored at $4^{\circ} \mathrm{C}$ in glass bottles covered in foil with Teflon-lined caps. Appropriate volumes of the stock solutions were added to a background solution to obtain the final E2 concentrations ranging from 0.05 to $2.0 \mathrm{mg} \mathrm{L}^{-1}$ for each experiment. The background solution consisted of an electrolyte, calcium chloride $\left(\mathrm{CaCl}_{2}\right)$, at a concentration of $5 \mathrm{mM}$ 
consistent with Lee et al. (2003) and Yu et al. (2004) and a biological inhibitor, sodium azide $\left(\mathrm{NaN}_{3}\right)$, at a concentration of $100 \mathrm{mg} \mathrm{L}^{-1}$ consistent with Yu et al. (2004). The final volumetric fraction of methanol in each E2 solution was $<0.5 \%$ $(\mathrm{v} / \mathrm{v})$, a concentration level at which no measurable effect of the cosolvent, methanol, has been found for sorption of organic pollutants (Yu et al., 2004). The chemicals used for the E2 solutions and the chemicals used for liquid/liquid extraction and derivatization procedures were analytical grade or better and purchased from Fisher Chemical, EMD Chemicals, Inc., Sigma Aldrich, or ACROS Organics.

\section{SoILS}

Samples representative of productive agricultural soils from three different physiographic regions of Virginia were collected previously by Lawrence (2000) from fields in the Appalachian Ridge and Valley, Piedmont, and Atlantic Coastal Plain regions. The Ridge and Valley soil was a Groseclose loam from Montgomery County, classified as a clayey, mixed mesic Typic Hapludult. The Coastal Plain soil was a Myatt fine sandy loam from Isle of Wight County, classified as a fine-loamy, siliceous, thermic Typic Ochraquult. The Piedmont soil was a Cecil loam from Amelia County, classified as a fine, kaolinitic, thermic Typic Kanhapludult. All soils were collected from the plow layer $(0$ to $15 \mathrm{~cm})$. An additional Cecil soil sample was collected from the Bt horizon.

Following collection, all soils were air-dried and clods were broken up using a mortar and pestle, sifted through a 2 $\mathrm{mm}$ sieve, and thoroughly homogenized by mixing in a portable electric cement mixer (Lawrence, 2000). The Virginia Cooperative Extension Soil Testing Laboratory at Virginia Tech determined $\mathrm{pH}$ (1:1 ratio of soil to water) and percent organic matter (Lawrence, 2000). Cation exchange capacity was determined by the Soil Survey Laboratory at Virginia Tech. Characteristics of each soil are listed in table 1. Before weighing for sorption experiments, the soil samples were dried for $24 \mathrm{~h}$ in a $100^{\circ} \mathrm{C}$ oven, and then mixed by hand.

For this study, the organic matter content of each soil was converted to organic carbon content by dividing by the Van Bemmelen factor of 1.724 (Richardson and Vepraskas, 2001). Although this is a common conversion, it is very general and is not always accurate for all soils. This conversion was used to compare the organic matter content of the soils used in this study to the organic carbon content of soils in published studies.

\section{Estrogen ANALYSIS by GC-MS}

To determine the concentration of E2 in the aqueous phase from the batch experiments containing soil and E2 solution, each sample was prepared using liquid/liquid extraction and

\begin{tabular}{|c|c|c|c|}
\hline Soil Type & $\mathrm{pH}$ & $\begin{array}{c}\mathrm{OC}^{[\mathrm{a}]} \\
(\%)\end{array}$ & $\begin{array}{c}\text { CEC } \\
\left(\mathrm{cmol}_{(+)} \mathrm{kg}^{-1}\right)\end{array}$ \\
\hline Groseclose & 6.7 & 2.2 & 5.45 \\
\hline Cecil & 6.6 & 1.8 & 4.61 \\
\hline Cecil Bt horizon & $\mathrm{ND}^{[\mathrm{b}]}$ & 0.1 & ND \\
\hline Myatt & 6.1 & 1.3 & 3.76 \\
\hline
\end{tabular}

[a] Organic carbon content was determined by dividing organic matter by 1.724 (Richardson and Vepraskas, 2001).

[b] $\mathrm{ND}=$ not determined. derivatization prior to analysis by gas chromatography-mass spectrometry (GC-MS). Samples were taken with glass pipettes from continuously mixed bottles to retain the soil-tosolution ratio. The supernatant was removed from each sample by centrifugation in glass centrifuge tubes $(750 \mathrm{~g}$ for 30 min at $22^{\circ} \mathrm{C}$ ). E2 was extracted twice from the supernatant by liquid/liquid extraction with dichloromethane (DCM). A mixture of O-bis(trimethylsilyl)trifluoroacetamide (BFTSA) and $1 \%(\mathrm{v} / \mathrm{v})$ trimethylsilylimidazole (TMSI) was used to derivatize the samples for GC-MS analysis. Similar to the derivatization method described by Ding and Chiang (2003), the dried extraction residue was resuspended with BFTSA with $1 \%(\mathrm{v} / \mathrm{v})$ TMSI. The resuspended samples were vortexmixed and heated at $70^{\circ} \mathrm{C}$ for $30 \mathrm{~min}$. The samples were then dried at $70^{\circ} \mathrm{C}$ under nitrogen. The derivatized and dried samples were resuspended in $1 \mathrm{~mL}$ hexane with $0.5 \mathrm{mg} \mathrm{L}^{-1}$ mirex as an internal standard for GC-MS analysis and transferred to $2 \mathrm{~mL}$ amber GC-MS vials. The samples were analyzed with an Agilent 6980 Series GC with a 5973 mass selective detector configured with a $30 \mathrm{~m}$ DB-5MS + DG capillary column (J \& W Scientific). The inlet temperature was $260^{\circ} \mathrm{C}$, and the GC temperature was initiated at $100^{\circ} \mathrm{C}$ for $2 \mathrm{~min}$, ramped at $20^{\circ} \mathrm{C}$ per min to $260^{\circ} \mathrm{C}$, and then ramped at $10^{\circ} \mathrm{C}$ per min to $290^{\circ} \mathrm{C}$. The carrier gas was helium and flowed at $1 \mathrm{~mL} \mathrm{~min}^{-1}$.

A calibration curve using standard solutions of $0.10,0.50$, 1.0, and $2.0 \mathrm{mg} \mathrm{L}^{-1} \mathrm{E} 2$ solution was constructed to relate the measured GC-MS response to the E2 concentration. Mirex and derivatized E2 and E1 peaks were identified by characteristic mass spectral fragments and verified by retention time. The characteristic mass spectral fragments were $\mathrm{m} / \mathrm{z}$ 416 for E2 and $m / z 342$ for E1 (Ding and Chiang, 2003).

To ensure quality control, the efficiency of the methods described above was evaluated by calculating the E2 recovery from spiked solutions of Groseclose soil water. Because it was not possible to separate the DCM liquid-liquid extraction efficiency and the derivatization efficiency, the E2 recovery efficiency is the total percent spiked E2 recovered after all sample processing steps and was calculated as $88 \%$. The method detection level (MDL) for E2 extracted from Groseclose soil-water systems was $0.03 \mathrm{mg} \mathrm{L}^{-1} \mathrm{E} 2$. Concentrations less than the MDL were not included in the isotherm development. The output from the GC-MS was checked for E1, the primary degradation product of E2. Standards containing $0.1,0.5,1.0$, and $2.0 \mathrm{mg} \mathrm{L}^{-1} \mathrm{E} 1$ and E2 were analyzed on the GC-MS to obtain relative peak responses for E1 and E2. This was needed to quantify the amount of E1 in the aqueous phase of each system.

Each set of experiments included controls with no soil at the highest and lowest E2 concentrations to ensure that E2 was sorbed to the added soil and not the glassware. Using data from the Groseclose soil experiments, the control for $0.05 \mathrm{mg}$ $\mathrm{L}^{-1}$ averaged $115 \%$ of the initial concentration, and the control for $2.0 \mathrm{mg} \mathrm{L}^{-1}$ averaged $99 \%$ of the initial concentration. Based on these results, it was concluded that sorption to the glassware was negligible.

Although the E2-soil systems were sterilized with sodium azide, each sample was checked for E2 degradation by measuring concentrations of E1. Many samples had a small amount of E1 formed from the degradation of a standard addition of E2 (table 2). The Cecil Bt soil had the lowest amount of E2 degradation. Because the GC-MS results were checked after the experiment for E1, an E1 calibration curve was developed to adjust aqueous E2 concentrations using the 
Table 2. Mean percent ratio of aqueous

E1 to total aqueous estrogen $(\mathrm{E} 1+\mathrm{E} 2)$.

\begin{tabular}{ccccc}
\hline \multirow{2}{*}{$\begin{array}{c}\text { Initial E2 } \\
\text { Concentration } \\
\left(\mathrm{mg} \mathrm{L}^{-1}\right)\end{array}$} & \multicolumn{4}{c}{$\begin{array}{c}\text { Mean Percent Ratio of Aqueous E1 } \\
\text { to Total Aqueous Estrogen }\end{array}$} \\
\cline { 2 - 5 } & Myatt & Cecil Bt & Cecil & Groseclose \\
\hline 0.1 & 2.2 & 0.0 & 13.1 & 7.4 \\
0.5 & 2.6 & 0.0 & 3.9 & 2.6 \\
1.0 & 3.7 & 0.2 & 4.4 & 1.5 \\
2.0 & 0.1 & 0.2 & 3.3 & 0.5 \\
\hline
\end{tabular}

E1 measured in each sample. The presence of E1 indicated that there was E2 degradation despite the addition of sodium azide, but the specific cause of the degradation in these systems could not be determined. It is suspected that either the sodium azide did not inhibit all biological degradation, or the E2 was degraded by abiotic means such as photolysis or iron oxide catalysis as suggested by Colucci et al. (2001).

\section{ISOTHERM DEVELOPMENT}

Isotherm (linear, Freundlich, and Langmuir) equations describing sorption for each soil were developed using aqueous E2 concentrations measured in each soil-water system and sorbed concentrations calculated using a mass balance. Data measured after $24 \mathrm{~h}$ for each soil were fitted to Freundlich, linear, and Langmuir isotherms using linear regression in SAS (SAS, 2003). Because E1 was present in the aqueous samples, the E2 measured in the aqueous phase was adjusted based on the E1 aqueous concentration so that any loss of E2 via degradation to E1 was not mistakenly attributed to sorption to soil. The aqueous E2 equivalent concentration was calculated as:

$$
C_{\mathrm{E} 2 \text { equiv }}=C_{\mathrm{E} 2}+C_{\mathrm{E} 1}\left(\frac{M W_{\mathrm{E} 2}}{M W_{\mathrm{E} 1}}\right)
$$

where $C_{\mathrm{E} 1}$ and $C_{\mathrm{E} 2}$ and $M W_{\mathrm{E} 1}$ and $M W_{\mathrm{E} 2}$ are the measured aqueous concentrations and molecular weights of $\mathrm{E} 1$ and $\mathrm{E} 2$, respectively. The aqueous E2 equivalent concentration and the sorbed E2 concentration (calculated by mass balance subtracting the E1 and E2 aqueous concentrations from the total mass of E2) were used in developing sorption isotherms. To compare this research to other estrogen sorption studies, the carbon-normalized partitioning coefficient $\left(K_{o c}\right)$ was calculated by dividing the linear partitioning coefficient $\left(K_{p}\right)$ by the organic carbon content of each soil (Essington, 2004).

\section{Results AND Discussion}

\section{ISOTHERMS}

Isotherm equations were used to model the equilibrium partitioning between sorbed E2 and aqueous E2. For all soils tested, equilibrium was reached within $24 \mathrm{~h}$ (fig. 2). The re-

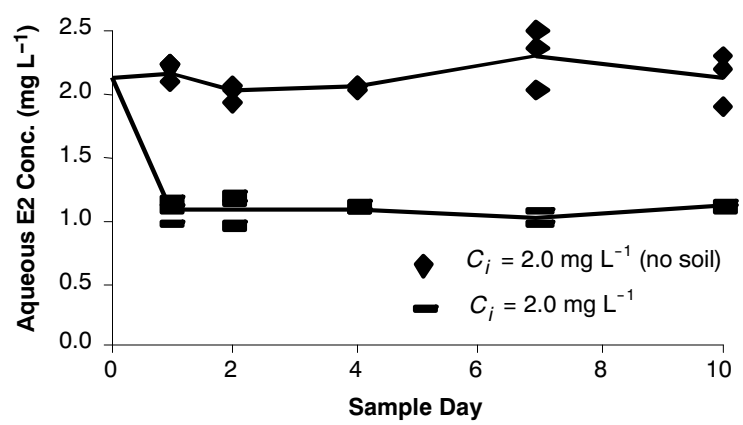

Figure 2. Aqueous E2 concentration by sample day for batch experiments using Groseclose soil and a control (no soil) for an initial E2 concentration of $2.0 \mathrm{mg} \mathrm{L}^{-1}$. These results were typical of other soils and initial concentrations.

sults indicate agreement with previous studies that found time to equilibrium within the order of one day (Lai et al., 2000; Casey et al., 2003) rather than 7 to 10 days as suggested by $\mathrm{Yu}$ et al. (2004). Because of the large range $(<24 \mathrm{~h}$ to 10 days) of previously reported time to equilibrium in aqueous E2 systems, no samples were taken before $24 \mathrm{~h}$ in this study; therefore, a more precise time to equilibrium could not be determined.

The linear isotherm fit the E2 sorption data best for Myatt, Cecil, and Cecil Bt horizon (table 3), and fit well for the Groseclose soil data. In contrast, the Freundlich isotherm fit the Groseclose soil data best. The Langmuir isotherm was not significant for Cecil, Cecil Bt horizon, or Myatt soils. Although the $\mathrm{R}^{2}$ value (0.91) was relatively high for the linear regression of the Langmuir isotherm using data from Groseclose soil, it is unlikely that the assumptions for the Langmuir isotherm describe sorption of E2 to Groseclose soil. The Langmuir isotherm was developed initially to describe the adsorption of gas molecules by a solid surface, and the assumptions are not generally applicable to soil systems (Essington, 2004).

Past E2 sorption studies have employed Freundlich isotherms (Lai et al., 2000; Casey et al., 2003; Lee et al., 2003; Yu et al., 2004). The sorption behavior of hydrophobic organic compounds, such as E2, is often described by linear isotherms (Essington, 2004), a special case of the Freundlich isotherm with $n=1$. The linear isotherms developed for Groseclose, Cecil, Myatt, and Cecil Bt soils are plotted in figure 3.

While the high $\mathrm{R}^{2}$ factors for Myatt, Cecil, and Groseclose soils indicate that isotherms can represent the sorption of E2, this experiment simplified the complex environmental conditions that would determine the aqueous E2 concentration by using sodium azide to inhibit biodegradation and by covering to minimize photolysis. In a field environment, degradation rates would play a role in the amount of E2 that is available for transport to surface water.

Table 3. Groseclose, Myatt, and Cecil soil sorption isotherm parameters.

\begin{tabular}{|c|c|c|c|c|c|c|c|c|}
\hline \multirow[b]{2}{*}{ Soil } & \multicolumn{2}{|c|}{ Linear } & \multicolumn{3}{|c|}{ Freundlich } & \multicolumn{3}{|c|}{ Langmuir } \\
\hline & $\mathrm{R}^{2}$ & $\begin{array}{c}K \\
\left(\mathrm{~L} \mathrm{~kg}^{-1}\right)\end{array}$ & $\mathrm{R}^{2}$ & $K$ & $n$ & $\mathrm{R}^{2}$ & $\begin{array}{c}K \\
\left(\mathrm{~L} \mathrm{~kg}^{-1}\right)\end{array}$ & $\begin{array}{c}b \\
\left(\mathrm{mg} \mathrm{kg}^{-1}\right)\end{array}$ \\
\hline Groseclose & 0.93 & 21.84 & 0.98 & 22.69 & 0.73 & 0.91 & 1.50 & 34.39 \\
\hline Myatt & 0.97 & 21.35 & 0.92 & 29.49 & 1.52 & 0.30 & $\mathrm{~ns}^{[\mathrm{a}]}$ & ns \\
\hline Cecil & 0.93 & 14.42 & 0.78 & 10.70 & 1.07 & 0.05 & ns & ns \\
\hline Cecil Bt & 0.73 & 9.88 & 0.63 & 13.79 & 1.04 & 0.00 & ns & ns \\
\hline
\end{tabular}

[a] ns = parameter not significant at $\alpha=0.05$. 


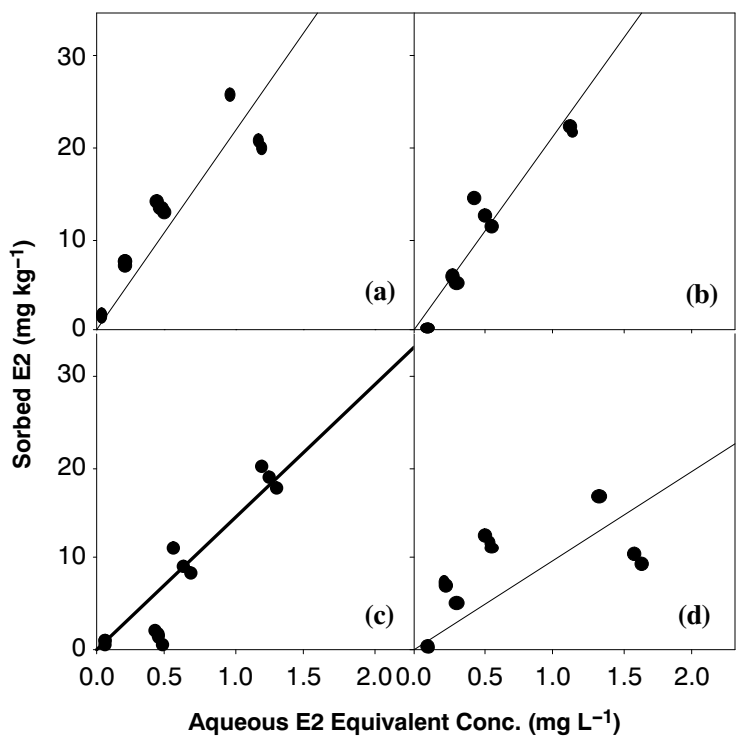

Figure 3. Linear isotherms for sorption of E2 to (a) Groseclose, (b) Myatt, (c) Cecil, and (d) Cecil Bt horizon soils. These isotherms were created using the equivalent $\mathrm{E} 2$ concentration (eq. 1).

Although the soil-water systems in this study were chemically sterilized with sodium azide, some E2 degraded to E1, suggesting that either there is an abiotic mechanism of degradation of $\mathrm{E} 2$, or that sodium azide at a level of $100 \mathrm{mg} \mathrm{L}^{-1}$ was not enough to inhibit biodegradation. Other studies investigating the degradation of E2 to E1 using methods of sterilization such as autoclaving and sodium azide have suggested that biological activity is the primary degradation mechanism (Mansell et al., 2004; Fan et al., 2007; Yu et al., 2004). The degradation of estrogen in the soil environment needs to be studied further with a variety of soil characteristics to adequately model the environmental fate of estrogen from landapplied manure. In the presence of degradation, competitive sorption between estrogen forms and other compounds would also complicate the environmental fate of these compounds. Competitive sorption between E1 and E2 has been observed in soil systems (e.g., Bonin and Simpson, 2007); however, the competitive effect is expected to be insignificant if the primary sorbate, E2, is at a high concentration compared to the secondary sorbate, E1 (Yu et al., 2004).

\section{EFFect of OC Content on Sorption OF E2}

For all soils on which animal manure was likely to be applied (i.e., the plow layer), the linear isotherm model provided an adequate fit $\left(\mathrm{R}^{2}>0.93 ; \alpha=0.05\right)$. The linear isotherm also provided the best fit of the three isotherms for the Bt horizon of the Cecil soil $\left(\mathrm{R}^{2}=0.73\right)$; however, care should be taken in applying this model to E2 sorption in soils such as the Cecil Bt horizon soil with low organic matter content. The major difference between the other soils in this study and the Cecil Bt horizon is the organic carbon content. It is hypothesized that the low organic carbon content of this soil is responsible for the difference in sorption behavior. However, more research needs to be done on soils with varying organic carbon contents to create isotherm equations for low organic carbon soils.

Soil organic matter or soil organic carbon content is highly correlated to the extent of sorption for hydrophobic compounds (USEPA, 1998; Essington, 2004). In this study, the

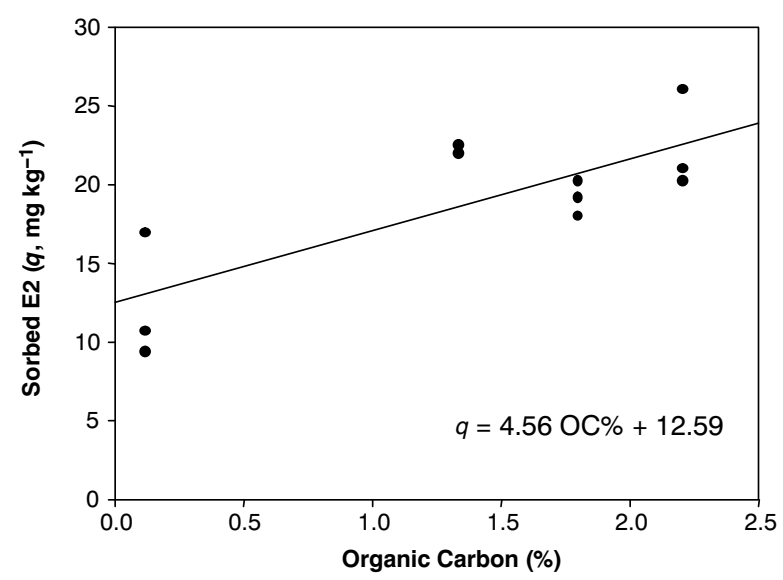

Figure 4. Correlation between sorbed E2 concentration and organic carbon content $(\%)$. Initial E2 concentration was $2.0 \mathrm{mg} \mathrm{L}^{-1}$ in $150 \mathrm{~mL}$ of background solution and $6.0 \mathrm{~g}$ soil.

soil with the highest organic carbon content, Groseclose (OC $\%=2.2$ ), had the greatest sorption of E2, and the soil with the lowest organic carbon content, Cecil Bt horizon (OC \% = $0.1)$, had the least sorption of E2. The Cecil soil had a higher organic carbon content $(\mathrm{OC} \%=1.8)$ than the Myatt soil (OC $\%=1.3$ ), but had a smaller partitioning coefficient. The partitioning coefficient is the slope of the linear isotherm (fig. 3). A steeper slope, or higher partitioning coefficient, indicates greater sorption of E2.

A correlation analysis was performed using SAS (SAS, 2003) between E2 sorption, and soil OC \% and CEC for the data used for isotherm development at an initial concentration of $2.0 \mathrm{mg} \mathrm{L}^{-1}$ (fig. 4). The Pearson correlation coefficient for soil OC \% and sorbed E2 was $0.79(\mathrm{p}=0.004)$. No significant correlation between CEC and sorption $(\mathrm{r}=0.11, \mathrm{p}=$ 0.79) was found, but there was a significant correlation between CEC and OC \% ( $\mathrm{r}=1.0, \mathrm{p}<0.0001)$. The CEC values used for this analysis were only for Cecil, Groseclose, and Myatt soils. No information regarding the CEC value of Cecil Bt soil was available. The sorption of E2 was correlated to OC $\%$ content $(r=0.79, p=0.004)$, which supports the hydrophobic partitioning theory suggested by Lee et al. (2003) as the dominant sorption mechanism for E2. Other studies reported strong correlations between organic carbon and sorption (Lai et al., 2000; Casey et al., 2003).

The partitioning coefficient, or slope, of the linear isotherms developed in this study did not increase in the order of increasing organic carbon content. Although Groseclose soil with the highest organic carbon content showed the strongest sorption of these soils, the linear isotherm developed for Myatt soil was very similar (fig. 3). Cecil soil has larger carbon content than Myatt soil, yet the slope of the linear isotherm developed for the Cecil soil was less than the slope of the linear isotherm developed for the Myatt soil. Therefore, linear partitioning to organic carbon may be the dominant sorption mechanism for the soils used in this study, but the E2 sorption cannot be completely represented by this mechanism.

\section{LoG $K_{O C}$ VALUES}

When the partitioning coefficient was normalized using the organic carbon content, the $\log K_{o c}$ coefficients for this study (table 4) were found to be comparable to those values published for other soils. Casey et al. (2005) reported $\log K_{o c}$ values ranging from 2.75 to 4.13 from the $24 \mathrm{~h}$ sample time. 
Table 4. Summary of partitioning coefficients $(K)$ and the organic carbon (OC) normalized $\left(\log K_{o c}\right)$ values for batch equilibrium E2 sorption experiments.

\begin{tabular}{ccccc}
\hline Soil & $K\left(\mathrm{~L} \mathrm{~kg}^{-1}\right)$ & OC \% & $\log K_{o c}$ & Reference \\
\hline Groseclose & 21.8 & 2.2 & 3.00 & This study \\
Myatt & 21.4 & 1.3 & 3.22 & This study \\
Cecil & 14.4 & 1.8 & 2.90 & This study \\
Cecil Bt horizon & 9.9 & 0.1 & 3.99 & This study \\
LaDelle & $89.5^{[\mathrm{a}]}$ & 9.2 & $2.97^{[\mathrm{a}]}$ & Casey et al., 2005 \\
Bearden & $110.9^{[\mathrm{b}]}$ & 7.5 & $3.17^{[\mathrm{a}]}$ & Casey et al., 2005 \\
Gardena & $78.4^{[\mathrm{b}]}$ & 5.3 & $3.17^{[\mathrm{a}]}$ & Casey et al., 2005 \\
Glydon & $445.2^{[\mathrm{b}]}$ & 3.3 & $4.13^{[\mathrm{a}]}$ & Casey et al., 2005 \\
Sioux & $42.2^{[\mathrm{b}]}$ & 7.5 & $2.75^{[\mathrm{a}]}$ & Casey et al., 2005 \\
Drummer & 83.2 & 2.91 & 2.46 & Lee et al., 2003 \\
EPA 1 & 3.56 & 0.22 & 3.21 & Lee et al., 2003 \\
\hline
\end{tabular}

[a] Parameters calculated from samples taken at $24 \mathrm{~h}$.

[b] $K$ was calculated using published $K_{O c}$ and $\mathrm{OC} \%$ values.

When the $\log K_{o c}$ values are compared within each study, the smallest values of OC \% result in the largest $\log K_{o c}$ values. There is not a general correlation across studies (table 4), but Casey et al. (2005) reported a negative correlation between organic carbon content and $\log K_{o c}$ values (correlation coefficient $=-0.87$ ), indicating that hydrophobic partitioning is not the only sorption mechanism. Similarly, our data show a strong negative correlation between $\log K_{o c}$ and $\mathrm{OC} \%(\mathrm{r}=$ -0.96). As organic carbon content decreases, the contribution of non-hydrophobic processes appears to increase. Yu et al. (2004) suggested one possible non-hydrophobic sorption mechanism where polar groups on E2 can readily interact with mineral surfaces. Because sorption of E2 varied with soil type, future studies should examine the mechanism of sorption and degradation of E2 to attempt to predict the behavior in different soils. The results of this study indicated that the organic carbon content of the soil plays an important role in determining the amount of sorption of E2; however, more work needs to be done to examine the behavior of E2 in relation to soil organic carbon and other soil components.

\section{Limitations of Isotherm Development Procedures}

The sorption of organic compounds can depend on a variety of environmental conditions such as temperature, $\mathrm{pH}$, and soil type. In these experiments, the $\mathrm{pH}$ was not buffered, and the temperature varied by $\pm 2^{\circ} \mathrm{C}$. Care must be taken when comparing these results to other studies such as $\mathrm{Yu}$ et al. (2004) where the $\mathrm{pH}$ of the soil-water systems was buffered to 6.8. To date, there are no studies reported in the literature examining the effect of $\mathrm{pH}$ on the sorption of $\mathrm{E} 2$ to soils. Variations associated with soil type such as clay type and content and organic carbon content can affect sorption of E2. The isotherms developed in this study were unique to each soil; therefore, the isotherms developed should not be applied to the sorption of E2 to other soils. The study of the sorption of estrogens can be further complicated by degradation by microorganisms, photolysis, and abiotic catalysis. Many isotherm studies measured only the aqueous sorbate concentration and calculated the sorbed concentration using a mass balance (e.g., USEPA, 1998; Lai et al., 2000; Yu et al., 2004); however, extracting and measuring the sorbed estrogen concentrations would have been useful in this study to distinguish between the amount of E2 sorbed and the amount degraded to E1 and other byproducts. Although efforts were made to prevent degradation of E2 by microbial and photoly- sis mechanisms for these experiments, some E1 was measured in many samples. This is a major limitation of attempting to isolate the sorption process from the overall environmental fate of a relatively easily degraded compound such as E2. In a natural system, both sorption and degradation would serve as processes to remove E2 from the soil solution.

\section{Summary AND CONClusions}

This study consisted of a series of batch equilibrium experiments to examine the sorption behavior of E2 to agricultural soils from different physiographic regions of Virginia. Initial E2 concentrations ranging from 0.05 to $2.0 \mathrm{mg} \mathrm{L}^{-1}$ were chosen to be representative of E2 concentrations in manure applications. The GC-MS methodology used in this study with liquid/liquid extraction and derivatization was an appropriate method to measure these estrogen concentrations in soil-water solutions (MDL of $0.03 \mathrm{mg} \mathrm{L}^{-1}$ and $88 \%$ recovery efficiency of E2 for the method). In general, linear isotherms described the sorption of E2 to agricultural soils at concentrations less than $2.0 \mathrm{mg} \mathrm{L}^{-1} \mathrm{E} 2$. The sorption of E2 to soil was correlated to the organic carbon content, and hydrophobic partitioning was assumed to be the dominant sorption mechanism of E2 to agricultural soils. However, hydrophobic partitioning does not fully describe the sorption of E2 to soils, especially for soils with low organic carbon content (< approx. 0.1\%), indicating that other sorption mechanisms may be masked by hydrophobic partitioning behavior in soils with high organic carbon content (> approx. $1.0 \%$ ). If the concentration of E2 in manure is known, then the linear isotherm parameters developed for Groseclose, Cecil, and Myatt soils can be used to estimate the concentration of E2 available for runoff from land-applied manure. These estimates can be used for manure application management decisions to protect aquatic wildlife.

\section{SugGeStions for Future RESEARCH}

While this study was focused on the free estrogen (E2), conjugated forms of estrogens are more polar and may be transported more easily in runoff (Hanselman et al., 2003). Unsuccessful attempts were made as part of this study to analyze estradiol glucuronides and sulfates by deconjugation, derivatization, and GC-MS analysis following the methanolysis deconjugation procedure described by Tang and Crone (1989). Future work should examine other methods, such as enzymatic hydrolysis to deconjugate conjugated estrogens, if GC-MS is to be used. Liquid chromatography-mass spectrometry (LC-MS) methods can also be used to analyze conjugated estrogens, as LC-MS eliminates the need to deconjugate and derivatize conjugated estrogens (Isobe et al., 2003). Conjugated estrogens have been largely ignored in sorption and degradation studies, but they may be important because they are expected to be much more soluble and, therefore, more easily transported.

\section{ACKNOWLEDGEMENTS}

Soils were provided by Dr. Lucian Zelazny from the Virginia Tech Department of Crop and Soil Environmental Sciences. All soil characterization was completed by the Virginia Tech Soil Testing Laboratory. GC-MS assistance was provided by Jody Smiley in the Virginia Tech Environmental Engineering Instrumentation Laboratory. Partial funding was 
provided by The Cooperative Institute for Coastal and Estuarine Environmental Technology (CICEET) and the Virginia Tech Department of Biological Systems Engineering.

\section{REFERENCES}

Andersen, H., H. Siegrist, B. Halling-Sorensen, and T. A. Ternes. 2003. Fate of estrogens in a municipal sewage treatment plant. Environ. Sci. and Tech. 37(18): 4021-4026.

Baronti, C., R. Curini, G. D'Ascenzo, A. Di Corcia, A. Gentili, and R. Samperi. 2000. Monitoring natural and synthetic estrogens at activated sludge sewage treatment plants and in a receiving river water. Environ. Sci. and Tech. 34(24): 5059-5066.

Bohn, H. L., B. L. McNeal, and G. A. O’Connor. 2001. Soil Chemistry. New York, N.Y.: John Wiley and Sons.

Bonin, J. L., and M. J. Simpson. 2007. Sorption of steroid estrogens to soil and soil constituents in single- and multi-sorbate systems. Environ. Toxicology and Chem. 26(12): 2604-2610.

Brion, F., C. R. Tyler, X. Palazzi, B. Laillet, J. M. Porcher, J. Garric, and P. Flammarion. 2004. Impacts of 17 beta-estradiol, including environmentally relevant concentrations, on reproduction after exposure during embryo-larval-, juvenile- and adult-life stages in zebrafish (Danio rerio). Aquatic Toxicology 68(3): 193-217.

Casey, F. X. M., G. L. Larsen, H. Hakk, and J. Simunek. 2003. Fate and transport of $17 \beta$-estradiol in soil-water systems. Environ. Sci. and Tech. 37(11): 2400-2409.

Casey, F. X. M., J. Simunek, J. Lee, G. L. Larsen, and H. Hakk. 2005. Sorption, mobility, and transformation of estrogenic hormones in natural soil. J. Environ. Qual. 34(4): 1372-1379.

Colborn, T., F. S. V. Saal, and A. M. Soto. 1993. Developmental effects of endocrine-disrupting chemicals in wildlife and humans. Environ. Health Perspectives 101(5): 378-384.

Colucci, M. S., H. Bork, and E. Topp. 2001. Persistence of estrogenic hormones in agricultural soils: I. $17 \beta$-estradiol and estrone. J. Environ. Qual. 30(6): 2070-2076.

Ding, W. H., and C. C. Chiang. 2003. Derivatization procedures for the detection of estrogenic chemicals by gas chromatography/ mass spectrometry. Rapid Comm. in Mass Spectrometry 17(1): 56-63.

Essington, M. E. 2004. Soil and Water Chemistry: An Integrative Approach. Boca Raton, Fla.: CRC Press.

Fan, Z. S., F. X. M. Casey, H. Hakk, and G. L. Larsen. 2007. Persistence and fate of 17 beta-estradiol and testosterone in agricultural soils. Chemosphere 67(5): 886-895.

Finlay Moore, O., P. G. Hartel, and M. L. Cabrera. 2000. 17 beta-estradiol and testosterone in soil and runoff from grasslands amended with broiler litter. J. Environ. Qual. 29(5): 1604-1611.

Hanselman, T. A., D. A. Graetz, and A. C. Wilkie. 2003. Manure-borne estrogens as potential environmental contaminants: A review. Environ. Sci. and Tech. 37(24): 5471-5478.

Hutchins, S. R., M. V. White, F. M. Hudson, and D. D. Fine. 2007. Analysis of lagoon samples from different concentrated animal feeding operations for estrogens and estrogen conjugates. Environ. Sci. and Tech. 41(3): 738-744.

Isobe, T., H. Shiraishi, M. Yasuda, A. Shinoda, H. Suzuki, and M. Morita. 2003. Determination of estrogens and their conjugates in water using solid-phase extraction followed by liquid chromatography-tandem mass spectrometry. J. Chromatography A 984(2): 195-202.

Jobling, S., M. Nolan, C. R. Tyler, G. Brighty, and J. P. Sumpter. 1998. Widespread sexual disruption in wild fish. Environ. Sci. and Tech. 32(17): 2498-2506.

Kolpin, D. W., E. T. Furlong, M. T. Meyer, E. M. Thurman, S. D. Zaugg, L. B. Barber, and H. T. Buxton. 2002. Pharmaceuticals, hormones, and other organic wastewater contaminants in U.S. streams, 1999-2000: A national reconnaissance. Environ. Sci. and Tech. 36(6): 1202-1211.
Lai, K. M., K. L. Johnson, M. D. Scrimshaw, and J. N. Lester. 2000. Binding of waterborne steroid estrogens to solid phases in river and estuarine systems. Environ. Sci. and Tech. 34(18): 3890-3894.

Lange, I. G., A. Daxenberger, B. Schiffer, H. Witters, D. Ibarreta, and H. H. D. Meyer. 2002. Sex hormones originating from different livestock production systems: Fate and potential disrupting activity in the environment. Analytica Chimica Acta 473(1-2): 27-37.

Lawrence, C. L. 2000. Effects of feeding phytase enzyme and HAP corn on solubility of phosphorus, copper, and zinc in turkey manure and manure-amended soils. MS thesis. Blacksburg, Va.: Virginia Polytechnic Institute and State University, Department of Crop and Soil Environmental Sciences.

Lee, H. B., and D. Liu. 2002. Degradation of 17 beta -estradiol and its metabolites by sewage bacteria. Water, Air, and Soil Pollution 134(1-4): 351-366.

Lee, L. S., T. J. Strock, A. K. Sarmah, and P. S. C. Rao. 2003. Sorption and dissipation of testosterone, estrogens, and their primary transformation products in soils and sediment. Environ. Sci. and Tech. 37(18): 4098-4105.

Lucas, S. D., and D. L. Jones. 2006. Biodegradation of estrone and 17 beta-estradiol in grassland soils amended with animal wastes. Soil Biol. and Biochem. 38(9): 2803-2815.

Mansell, J., J. E. Drewes, and T. Rauch. 2004. Removal mechanisms of endocrine disrupting compounds (steroids) during soil aquifer treatment. Water Sci. and Tech. 50(2): 229-237.

Matsui, S., H. Takigami, T. Matsuda, N. Taniguchi, J. Adachi, H. Kawami, and Y. Shimizu. 2000. Estrogen and estrogen mimics contamination in water and the role of sewage treatment. Water Sci. and Tech. 42(12) (12): 173-179.

Nichols, D. J., T. C. Daniel, P. A. Moore, Jr., D. R. Edwards, and D. H. Pote. 1997. Runoff of estrogen hormone 17 beta-estradiol from poultry litter applied to pasture. J. Environ. Qual. 26(4): 1002-1006.

Raman, D. R., E. L. Williams, A. C. Layton, R. T. Burns, J. P. Easter, A. S. Daugherty, M. D. Mullen, and G. S. Sayler. 2004. Estrogen content of dairy and swine wastes. Environ. Sci. and Tech. 38(13): 3567-3573.

Richardson, J. L., and M. J. Vepraskas. 2001. Wetland Soils Genesis, Hydrology, Landscapes, and Classification. Boca Raton, Fla.: Lewis Publishers.

SAS. 2003. SAS ver. 9.1. Cary, N.C.: SAS Institute, Inc.

Shore, L. S., and M. Shemesh. 2003. Naturally produced steroid hormones and their release into the environment. Pure and Applied Chem. 75(11-12): 1859-1871.

Shore, L. S., D. L. Correll, and P. K. Chakraborty. 1995. Relationship of fertilization with chicken manure and concentration of estrogens in small streams. In Animal Waste and the Land-Water Interface, 155-162. K. Steele, ed. Boca Raton, Fla.: Lewis Publishers.

Tang, P. W., and D. L. Crone. 1989. A new method for hydrolyzing sulfate and glucuronyl conjugates of steroids. Analytical Biochem. 182(2): 289-294.

Ternes, T. A., M. Stumpf, J. Mueller, K. Haberer, R. D. Wilken, and M. Servos. 1999. Behavior and occurrence of estrogens in municipal sewage treatment plants: I. Investigations in Germany, Canada, and Brazil. Sci. Total Environ. 225(1-2): 81-90.

USEPA. 1998. Fate, transport, and transformation test guidelines: OPPTS 835.1220 sediment and soil adsorption/desorption isotherm. EPA 712-C-98-048. Washington, D.C.: U.S. Environmental Protection Agency.

Van Emmerik, T., M. J. Angove, B. B. Johnson, J. D. Wells, and M. B. Fernandes. 2003. Sorption of 17 beta-estradiol onto selected soil minerals. J. Colloid and Interface Sci. 266(1): 33-39.

Yu, Z. Q., B. H. Xiao, W. L. Huang, and P. Peng. 2004. Sorption of steroid estrogens to soils and sediments. Environ. Toxicology and Chem. 23(3): 531-539. 
